\title{
Peroral endoscopic myotomy (POEM) is more cost-effective than laparoscopic Heller myotomy in the short term for achalasia: economic evaluation from a randomized controlled trial
}

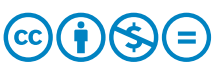

\author{
Authors \\ Institutions \\ 1 University of São Paulo School of Medicine Hospital das \\ Clínicas, São Paulo, Brazil \\ 2 Department of Transplantation, Gastroenterology \\ Division, University of São Paulo School of Medicine \\ Hospital das Clínicas, São Paulo, Brazil \\ 3 Endoscopy, Gastroenterology Division, University of São \\ Paulo School of Medicine Hospital das Clínicas, São \\ Paulo, Brazil
}

Tatiana Morgado Conte ${ }^{1}$, Luciana Bertocco de Paiva Haddad², Igor Braga Ribeiro ${ }^{3}$, Eduardo Turiani Hourneaux de Moura' ${ }^{1}$, Luiz Augusto Carneiro D’Albuquerque², Eduardo Guimarães Hourneaux de Moura ${ }^{3}$

submitted 10.6 .2020

accepted after revision 18.8 .2020

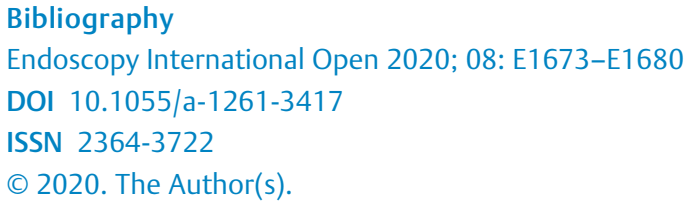

This is an open access article published by Thieme under the terms of the Creative Commons Attribution-NonDerivative-NonCommercial License, permitting copying and reproduction so long as the original work is given appropriate credit. Contents may not be used for commecial purposes, or adapted, remixed, transformed or built upon. (https://creativecommons.org/licenses/by-nc-nd/4.0/)

Corresponding author

Igor Braga Ribeiro, MD, Av. Dr. Enéas de Carvalho Aguiar, 255 - Instituto Central - Prédio dos Ambulatórios - Pinheiros, CEP: 05403-000 - São Paulo, SP, Brazil

Phone: +55-92-981377788

igorbraga1@gmail.com

\section{ABSTRACT}

Background and study aims We aimed to perform an economic evaluation of peroral endoscopic myotomy (POEM) and laparoscopic Heller myotomy (LHM) for the treatment of achalasia.

Materials and methods An economic cost-utility analysis was carried out over a time horizon of 1 year. Patients with achalasia who were admitted to the gastroenterology outpatient clinic of a public tertiary referral hospital were assigned to undergo POEM or LHM. The monetary amounts were extracted from the intranet of the institution using microcosting. All costs associated with the procedure, hospitalization, clinical follow-up and resolution of therapeutic complications were included. The utility data were measured in quality-adjusted life years (QALYs), which were estimated from the scores of a quality-of-life questionnaire.

Results Forty patients (20 POEM patients and 20 LHM patients) were included. The final cost associated with POEM and LHM was US\$2,619.19 \pm 399.53 and US\$1,696.44 \pm 412.21, respectively $(P<0.001)$. However, the QALYs in the POEM group $(0.434 \pm 0.215$ vs $0.332 \pm 0.222, P=0.397)$ were slightly higher than those in the LHM group. The incremental cost-utility ratio (ICUR) suggested that an additional US\$9,046.41/QALY gained was required when using POEM.

Conclusion For the treatment of achalasia in the public health system, POEM appears to be more cost-effective than LHM in the short term.

\section{Introduction}

Achalasia is a rare esophageal motility disorder characterized by aperistalsis in the esophageal body and incomplete relaxation of the lower esophageal sphincter (LES) in response to swallowing [1-8], with progressive dysphagia from solids to liquids being the most important clinical manifestation [9-12]. Currently, laparoscopic Heller myotomy (LHM) with fundoplication is considered the standard first-line therapy for achalasia $[1-6,13,14]$.
Inoue et al. [15] introduced the concept of natural orifice transluminal endoscopic surgery (NOTES) $[16,17]$ associated with submucosal dissection [18] and named this technique peroral endoscopic myotomy (POEM). Studies have shown that the short- to mid-term efficacy of POEM is greater than $90 \%$ and that the procedure is associated with less postoperative pain [19-25]. However, this procedure is frequently associated with some common adverse effects, such as pneumoperitoneum and surgical emphysema [26]. 
Although this new treatment could revolutionize the treatment of achalasia, the lack of knowledge regarding its costs and learning curve are barriers to its adoption in clinical practice. The aim of this study was to conduct a comparative costutility analysis of POEM and LHM with fundoplication.

\section{Materials and methods}

This economic pilot study consisted of a prospective economic cost-utility evaluation from a randomized controlled trial comparing POEM and LHM with fundoplication. Data were collected from a public tertiary university hospital for a period of 1 year. This study was approved by the ethics committee of the Faculty of Medicine of the University of São Paulo.

\section{Randomized controlled trial}

The randomized controlled trial was prospective, randomized, and conducted in a single center. This study was approved by the ethics committee of the Faculty of Medicine of the University of São Paulo and it was register in Clinical Trial by the number NCT02138643.

A simple randomization was carried out of patients diagnosed with symptomatic esophageal achalasia, eligible for the study and admitted on Gastrointestinal Department of the institution.

\section{Patients}

The patient inclusion criteria were: diagnosis of chagasic or idiopathic achalasia; age between 18 and 60 years; dysphagia score $\geq 1$; and Eckhardt score $>3$.

The exclusion criteria were: prior treatment for achalasia; prior esophageal, mediastinal or gastric surgery; pseudoachalasia; hepatic cirrhosis; esophageal varices; Barrett's esophagus; esophageal stenosis; malignant esophageal lesions; esophageal distal diverticulum; and coagulopathy.

\section{Interventions}

\section{Peroral endoscopic myotomy}

POEM was performed while the patient was under general anesthesia with positive pressure ventilation and $\mathrm{CO}_{2}$ insufflation. $\mathrm{A}$ submucosal tunnel was created approximately 2 or $3 \mathrm{~cm}$ below the gastroesophageal transition (GET), and $10 \mathrm{~mL}$ of saline with methylene blue was injected into the posterior wall of the midesophagus.

ENDO CUT Q configuration of ERBE VIO (ERBE, Elektromedizin $\mathrm{GmbH}$, US) equipment was used to create the submucosal tunnel. This configuration was selected considering that it is an alternating, monopolar and high frequency cutting mode that is characterized by alternating cutting and coagulation cycles.

After creating an adequate submucosal tunnel and performing haemostatic revision, myotomy of the distal $(2$ to $3 \mathrm{~cm}$ below the GET) to proximal (up to $8 \mathrm{~cm}$ above the GET and approximately $2 \mathrm{~cm}$ below the mucosal access) region was performed. SPRAY COAG (ERBE, Elektromedizin $\mathrm{GmbH}$ ) configuration was also used to ensure effective surface coagulation with- out contact with depth of thermal penetration, being suitable for tissue devitalization and to stop diffuse bleeding. In addition, the submucosal tunnel was performed using T-type hybrid knives (ERBE, Elektromedizin $\mathrm{GmbH}$ ) and ERBEJet2 pump cartridges (ERBE, Elektromedizin $\mathrm{GmbH}$ ).

Total myotomy, which involved sectioning of the longitudinal muscle fibers, allowed endoscopic passage without resistance through the GET. After revision of the mucosal aspect of the esophagus and stomach with thermal or surgical probing in the submucosal tunnel, the mucosal access was closed with clips.

Resolution Clip (Resolution Clips, Boston Scientific, Natick, Massachusetts, United States) was used to close the endoscopic myotomy. The choice of this device took into account the high retention rate, greater penetration into the tissue, possibility of repositioning, and ease of handling.

\section{Laparoscopic Heller MYOTOMY WITH FUNDOPLICATION}

LHM was performed with the patient under general anesthesia. Five to six incisions were made in the abdominal region to introduce the trocars. After the introduction of five or six trocars, the gastric vessels were sectioned, and the gastric fundus was mobilized. Then, the GET was dissected, and the hepatogastric ligament membrane was sectioned.

The diaphragmatic pillars were dissected, and the esophagus was isolated from the gap; the adhesions in the mediastinum were disconnected. Then, myotomy was performed by sectioning the muscle fibers in the LES and advancing $3 \mathrm{~cm}$ into the stomach and at least $6 \mathrm{~cm}$ into the esophagus. Hiatoplasty (approximation of the diaphragm abutments) was performed at separate points.

Fundoplication was performed by means of three suture lines (Pinotti's technique) covering the entire myotomy as follows: the first line was between the posterior wall of the esophagus and the posterior wall of the stomach; the second line was between the left lateral wall of the esophageal myotomy and the gastric fundus between the transition from the anterior to the posterior wall; and the third line was between the right lateral wall of the esophageal myotomy and the anterior surface of the gastric fundus.

\section{Economic analysis}

Direct medical costs were obtained via prospective data collection from the local database of the institution and estimated using microcosting. The costs were obtained in Brazilian Real $(R \$)$ in January 2017 and adjusted using the Broad National Consumer Price Index from the period (2.61897\%), followed by conversion to United States dollars (US\$) in August 2018 (US\$1.00=R\$3.77).

The study included all direct medical costs associated with the treatment in the time horizon of the study and represented the institution's direct monetary expenses for the treatment and clinical follow-up of the patient. - Table 1 shows how the monetary data were obtained. The costs were grouped into three categories: intraoperative, postoperative and clinical follow-up. 
- Table 1 Description of the methodology for obtaining cost data.

\begin{tabular}{|c|c|c|}
\hline Department & Component & Costs \\
\hline Human Resources & $\begin{array}{l}\text { Doctors, nurses, physiotherapists, and administrative } \\
\text { professionals }\end{array}$ & $\begin{array}{l}\text { Based on the standard cost indicated in the hospital budget per } \\
\text { profession per month divided by the time required for treatment }\end{array}$ \\
\hline Pharmacy sector & Medicine and hospital material & Based on the unit values paid in the last public bidding \\
\hline Medicinal gases & Oxygen, nitrous oxide, carbon dioxide, and nitrogen & Based on the cost of medical gas per liter per minute \\
\hline Laboratory sector & Laboratory examinations & Based on the unit price of each laboratory examination \\
\hline Imaging sector & $\begin{array}{l}\text { Esophageal manometry, upper digestive endoscopy, } \\
\text { abdominal ultrasound, and electrocardiogram }\end{array}$ & Based on the unit price of each imaging examination \\
\hline
\end{tabular}

- Table2 Baseline demographics.

\begin{tabular}{|c|c|c|c|}
\hline & POEM $(n=20)$ & $\operatorname{LHM}(n=20)$ & $P$ value \\
\hline Male, n (\%) & $12(60)$ & $14(70)$ & 0.507 \\
\hline Age (years), average \pm SD (range) & $44.9 \pm 14.6(21-72)$ & $44.2 \pm 13.2(21-64)$ & 0.875 \\
\hline \multicolumn{4}{|l|}{ Aetiology of achalasia, $n$ (\%) } \\
\hline Chagasic & $5(25)$ & $4(20)$ & \\
\hline Idiopathic & $15(75)$ & $16(80)$ & \\
\hline Eckardt score, average (range) & $8.0 \pm 1.7(6-9.00)$ & $8.5 \pm 1.9(7.25-9.75)$ & 0.558 \\
\hline \multicolumn{4}{|l|}{ Tolerated diet, n (\%) } \\
\hline - Without dysphagia & 0 & 0 & \\
\hline - Solid dysphagia & $4(20)$ & $4(20)$ & \\
\hline - Pasty dysphagia & $5(25)$ & $4(20)$ & \\
\hline - Liquid dysphagia & $10(50)$ & $12(60)$ & \\
\hline - Total dysphagia & $1(5)$ & 0 & \\
\hline LES pressure $(\mathrm{mmHg})$, average \pm SD (range) & $34.6 \pm 11.3(16.1-55.5)$ & $29.4 \pm 9.8(20.4-59)$ & 0.177 \\
\hline
\end{tabular}

The first category included monetary data associated with the procedure and anesthetic recovery. The second category comprised the costs from the immediate postoperative period until up to 30 days after the procedure, including costs due to complications. Finally, the third category covered all of the costs of clinical follow-up, such as medical interviews and conventional and high-resolution esophageal manometry and endoscopy. Medical interviews and endoscopic examinations were performed at one, six and 12 months. Conventional and high-resolution esophageal manometry were performed at 6 and 12 months.

\section{Utility}

Quality-adjusted life years (QALYs) were used to measure efficacy, being defined as a year of life with remission of achalasia symptoms. The QALYs is a generic measure of disease burden, including the quality and the quantity of life lived. The QALYs of each patient were estimated for one year, respecting the time horizon. The participants used this instrument to self-record their health status in the following five areas: mobility, self-care, usual activities, pain/discomfort and anxiety/depression.

The QALY instrumental was applied at two points during a clinical consultation: immediately after randomization and in the last cycle of the time horizon. The purpose of the first point was self-assessment of health status before the procedure, while the goal of the second point was to identify the degree of improvement in self-assessment 1 year after treatment. The difference in the first and second QALYs was assumed to be directly related to the intervention for achalasia.

\section{Statistical analysis}

The results are presented as the average and standard deviation. The monetary results are described as the average and standard deviation. Student's t-test was used to compare averages.

To test the hypothesis that both treatments are equally effective, a non-parametric repeated-measures analysis of variance (ANOVA) model was used $[27,28]$. The $95 \%$ confidence intervals $(\mathrm{Cls})$ were calculated and a two-tailed alpha of 0.05 
- Table 3 Short-term outcomes of POEM and LHM.

\begin{tabular}{|c|c|c|c|}
\hline & POEM $(n=20)$ & LHM $(n=20)$ & $P$ value \\
\hline Technical success rate, $\mathrm{n}(\%)$ & $20(100)$ & $20(100)$ & - \\
\hline Length of myotomy $(\mathrm{cm})$, average $\pm S D$ & & & 0.001 \\
\hline Total & $10.9 \pm 1.1$ & $8.3 \pm 1.5$ & \\
\hline Esophageal myotomy & $7.3 \pm 1.2$ & $5.5 \pm 1.1$ & \\
\hline Gastric myotomy & $3.6 \pm 0.7$ & $2.8 \pm 0.7$ & \\
\hline Operative duration (minutes), average \pm SD & $95.7 \pm 30.5$ & $218.7 \pm 50.9$ & 0.001 \\
\hline Length of hospital stay (days), average & 3.7 & 5.4 & 0.009 \\
\hline Recurrence of dysphagia, n (\%) & $1(5)$ & - & 0.001 \\
\hline Complication rate, $\mathrm{n}(\%)$ & $9(64,3)$ & $5(35,7)$ & 0.016 \\
\hline Low-risk complications, $\mathrm{n}$ & 7 & - & \\
\hline Subcutaneous emphysema & 3 & - & \\
\hline Bleeding & 3 & - & \\
\hline Bronchoaspiration & 1 & - & \\
\hline High-risk complications, n & 2 & 5 & \\
\hline Pleural effusion & - & 1 & \\
\hline Pneumonia & - & 1 & \\
\hline Esophageal or gastric iatrogenic perforation & 2 & - & \\
\hline Pneumothorax & - & 2 & \\
\hline Hemothorax & - & 1 & \\
\hline \multicolumn{4}{|l|}{ LES pressure $(\mathrm{mmHg})$, average $\pm \mathrm{SD}$} \\
\hline . 6 months & $15.8 \pm 7.4$ & $14.4 \pm 6.8$ & 0.448 \\
\hline . 12 months & $19.2 \pm 7.1$ & $13.4 \pm 3.3$ & 0.073 \\
\hline \multicolumn{4}{|l|}{ Eckardt score, average \pm SD } \\
\hline - 6 months & $1.0 \pm 1.4$ & $0.2 \pm 0.5$ & 0.186 \\
\hline - 12 months & $0.6 \pm 1.2$ & $0.4 \pm 0.7$ & 0.380 \\
\hline
\end{tabular}

LES, lower oesophageal sphincter; LHM, laparoscopic Heller myotomy with fundoplication; POEM, peroral endoscopic myotomy; SD, standard deviation.

was used in the hypothesis test. The tests were performed using R Software and Excel 2017.

\section{Cost-utility analysis}

A cost-utility analysis was performed in which the incremental cost-utility ratio (ICUR) was estimated using the final costs and the differences in the pre-procedure and post-procedure efficacy derived from the patient interviews to determine the incremental cost per QALY gained. The ICUR was calculated as the result between in the total cost of POEM and LHM divided by the difference in the utility between the therapeutic alternatives.

Uncertainty regarding the ICUR was determined by a sensitivity analysis, which considered the costs and QALYs associated with minor and major complications in each group. Minor complications were defined as bronchoaspiration, subcutaneous emphysema and intraoperative bleeding during myot- omy; major complications included esophageal or gastric iatrogenic perforation, pneumothorax, hypertension, pneumonia, haemothorax and pleural effusion. These results were compared with the reference ICUR.

\section{Results}

In total, 40 patients with achalasia were recruited; 20 patients were treated with POEM, and 20 patients were treated with LHM. The demographic data and the details of the POEM and LHM procedures are summarized in > Table 2 and $>$ Table 3. POEM and LHM were successfully completed in all patients (technical success rates, $100 \%, P=1.000$ ), and the operative duration of the endoscopic procedure was half of that for the surgical procedure $(P=0.001)$. The total myotomy extent in the POEM group was on average $1.5 \mathrm{~cm}$ greater than that in 
the LHM group $(P=0.001)$. The patients who underwent POEM had shorter hospital stays than did the patients who underwent LHM $(P=0.009)$.

Fourteen adverse events (AEs) (35\%) were observed in 12 of 40 patients, including three patients in the LHM group and nine in the POEM group $(P=0.016)$. AEs were classified as low risk, including subcutaneous emphysema, bleeding, and bronchoaspiration, and high risk, including pleural effusion, pneumonia, esophageal or gastric iatrogenic perforation, pneumothorax, and hemothorax.

All five complications in LHM patients were high risk: one case of pleural effusion, one case of pneumonia, two cases of pneumothorax, and one case of hemothorax. In the POEM group, seven complications were low risk: three cases of subcutaneous emphysema, three cases of bleeding, and one case of bronchoaspiration. Two patients had high-risk complications, including two cases of esophageal or gastric iatrogenic perforation.

Of the 40 patients involved in the study, 37 underwent upper digestive endoscopy in 1 month, 34 in 6 months and 35 in 1 year. The reflux rate was $64.6 \%$ in POEM and $11.1 \%$ in LHM $(P<0.002)$. The esophagitis rate was significantly higher in POEM in all periods $(P=0.014 ; P<0.001 ; P=0.002)$. After 1 month, 6 months, and 1 year, esophagitis rates were $0 \%, 5.6 \%$ and $11.1 \%$ in LHM and $29.4 \%, 62.5 \%$ and $64.6 \%$ in POEM, respectively.

At 3 months $57 \%$ of patients who had POEM and $20 \%$ who had LHM had reflux esophagitis. In the POEM group, esophagitis was observed in five patients in 1 month (Grade A: 1; Grade B: 3 and Grade C: 1 ); 10 patients in 6 months (Grade A: 3; Grade B: 2 and Grade C: 5) and 11 patients in 1 year (Grade A: 5; Grade B: 4 and Grade C: 2). These patients were treated conservatively with oral use of proton pump inhibitors. In the LHM group, one patient had esophagitis at 6 month (Grade $A$ ) and two patients at 1 year (Grade B: 1; Grade C: 1 ).

The Eckardt score and LES pressure were significantly reduced in both groups during all cycles of the time horizon, although they were similar in both groups independent of the cycle analyzed ( $\triangleright$ Table 3 ).

\section{Costs}

The total cost, including the costs incurred intraoperatively, postoperatively and during the follow-up period, was US\$ $86,312.63$, and POEM was responsible for $60.7 \%$ (US\$ $52,383.85)$ of this value. The average cost per patient in the POEM group was significantly higher than that in the LHM group (US\$2,619.19 \pm 399.53 vs $1,696.44 \pm 412.21, P<0.001$ ).

Costs incurred intraoperatively accounted for $56 \%$ (US\$ $48,335.07$ ) of the total cost. Although this period represented the component with the highest financial cost in both groups, the cost in the LHM group was half of the cost in the POEM group $(P<0.001)$ ( $>$ Fig. 1$)$.

The component with the second highest financial cost $(25 \%$, US $\$ 21,620.51$ ) was the postoperative period; on average, the cost in the LHM group was $22 \%$ less than that in the POEM group $(P<0.001)$ ( $>$ Fig. 1$)$.

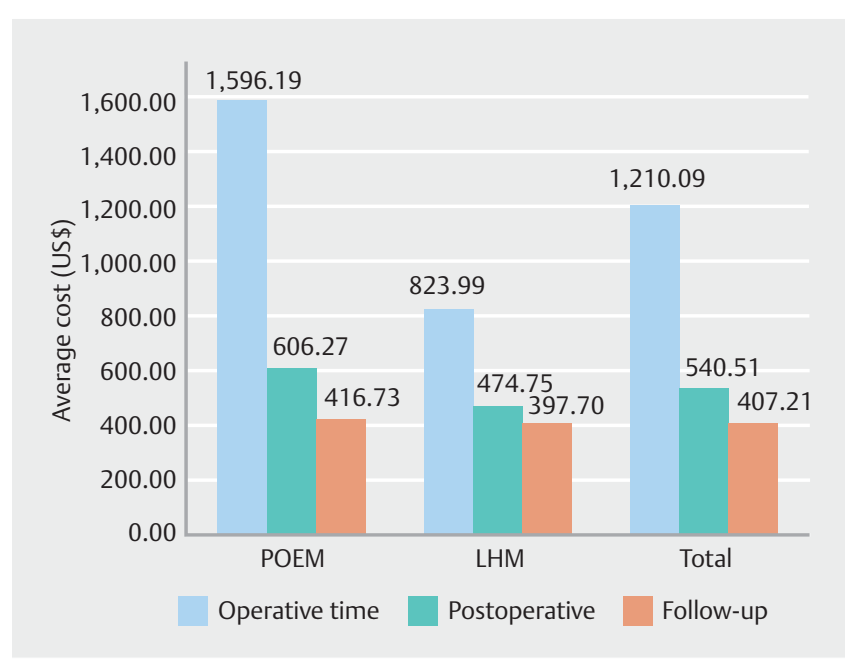

Fig. 1 Comparison of the average cost of POEM and LHM for each cost component.

Overall, the average cost of complications was higher in the POEM group than in the LHM group. For POEM patients without complications, the average cost was US\$2,477.60 $\$ 158.01$, while for POEM patients with minor and major complications, the average cost was US\$2,527.99 \pm 163.53 and US\$3,666.78 \pm 375.22 , respectively. The average cost in the LHM group was US $\$ 1,621.67 \pm 246.22$ and US\$2,120.13 \pm 901.33 for patients without and with major surgical complications, respectively.

\section{QALYs}

QALYs did not significantly differ between the groups before the procedure $(\mathrm{POEM}=0.506 \pm 0.181$ vs $\mathrm{LHM}=0.653 \pm 0.083$, $P>0.05)$. Over the time horizon, the QALYs increased in both groups (POEM $=0.940 \pm 0.200$ vs $\mathrm{LHM}=0.985 \pm 0.069$, $P=0.385)$. The difference between the final and preoperative QALYs for POEM and LHM was $0.434 \pm 0.164$ and $0.332 \pm 0.100$, respectively; however, this difference was not significant $(P=$ 0.397).

\section{Cost-utility analysis}

The difference in the final cost of the interventions was US\$ 922.75, and the difference in the final QALYs was 0.102. Therefore, the ICUR was US\$9,046.41/QALY.

\section{Sensitivity analysis}

The sensitivity analysis revealed variation in the ICUR when we analyzed the costs of major and minor complications and the clinical success in both groups ( $\$$ Fig. 2 ). The ICUR was directly proportional to the cost of POEM and, consequently, inversely proportional to LHM. Major endoscopic complications associated with the treatment of mucosal perforation increased the ICUR by $114 \%$ compared to the reference ICUR because the cost of POEM in this situation increased $40 \%$ (US $\$ 3,666.78 \pm$ 375.22 vs US\$2,619.19 $\$ 399.53)$.

In contrast, the clinical success of POEM decreased the ICUR by $17 \%$ because the cost of POEM was $5.5 \%$ lower than the reference cost (US\$2,477.60 \pm 158.01 vs US\$2,619.19 \pm 399.53 ). 


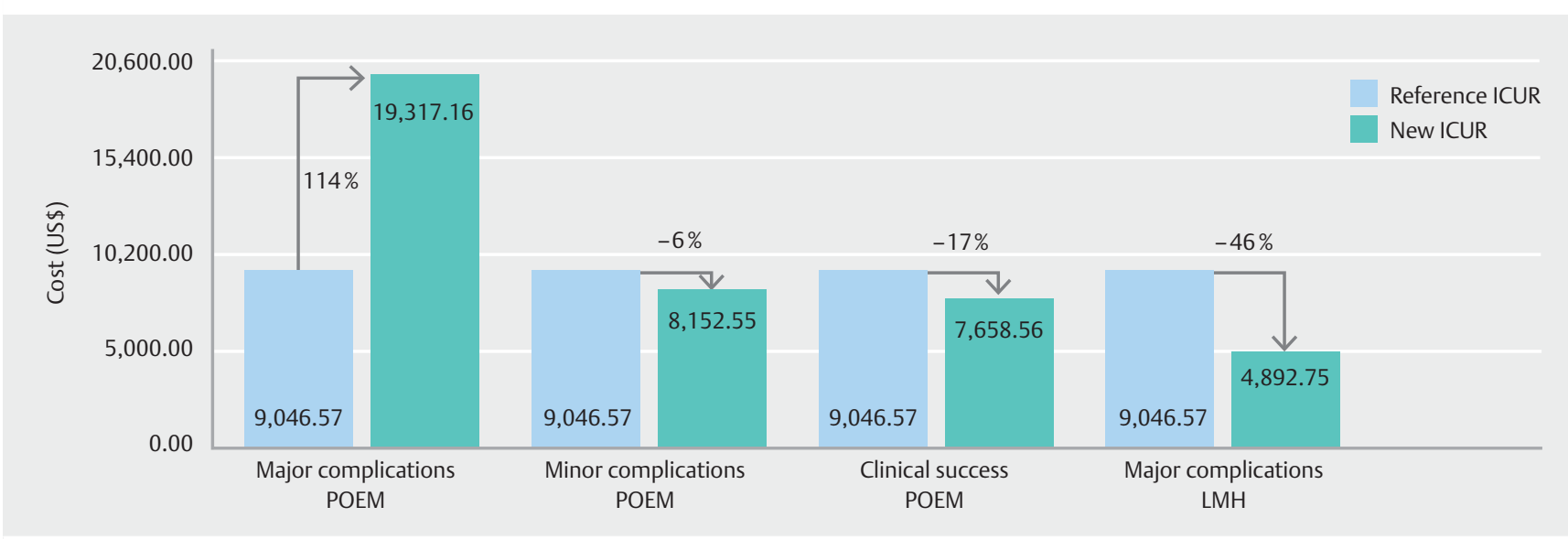

- Fig. 2 Sensitivity analysis of POEM and LHM comparing the reference ICUR with ICUR from major, minor, and clinical success of each group. The ICUR was calculated as the difference in cost of POEM and LHM divided by the difference in QALYS of POEM and LHM of according with each condition analyzed. The arrow indicates the percentage of impact of the ICUR result comparing reference ICUR with ICUR of the condition analyzed.

Similarly, when a major surgical complication occurred, the cost of LHM increased by $25 \%$ (US\$2,120.13 \pm 901.33 vs U\$ $1,696.44 \pm 412.21)$ and, consequently, the ICUR decreased by $46 \%$ (US\$4.892,74 vs US\$9,046.41/QALY).

\section{Discussion}

Until recently, the only options available for treatment of achalasia were pharmacological treatments, Botox, pneumatic dilation, and surgery [29]. However, technological progress and the development of minimally invasive surgery have allowed the creation of NOTES $[16,17]$ associated with submucosal dissection [18], and the called POEM, revolutionizing the treatment of achalasia [30-33].

This study is the first economic evaluation of achalasia management strategies and was performed using data from a prospective randomized controlled study based on real public costs. These costs were analyzed using a bottom-up analysis, which is an economic methodology that guarantees a high degree of detail and precision in determining costs for health institutions $[34,35]$, as the monetary values exactly reflect the reality of health system costs.

This economic methodology differs from previous economic studies $[19,20]$ based on results extracted retrospectively, in which main disadvantage is the lack of precision in collecting cost data. The total cost of POEM and LHM was US\$2,619.19 \pm 399.53 and US $\$ 1,696.44 \pm 412.21$, respectively $(P<0.001)$. In addition, the QALYs associated with POEM were slightly higher than those associated with LHM $(0.434 \pm 0.164$ vs $0.332 \pm$ $0.100, P=0.397$ ).

Thus, the ICUR was US $\$ 9,046.41 /$ QALY, which is consistent with previous reports $[19,20]$. The component with the highest financial cost in our study was the intraoperative period, with POEM costing twice as much as LHM $(P<0.001)$. This difference could be explained by: (1) the high cost of disposable endoscopic materials; and (2) the use of depreciated equipment in public hospitals.
Disposable endoscopic materials, including metal clips (Resolution Clips, Boston Scientific, Natick, Massachusetts, United States), T-type hybrid knives (ERBE, Elektromedizin GmbH, GA, US) and ERBEJet2 pump cartridges (ERBE, Elektromedizin $\mathrm{GmbH}$ ), accounted for $75 \%$ (US $\$ 23,933.23$, average US\$ $1,196.66 \pm 285.39$ per patient) of the intraoperative cost of POEM. In Brazil, these materials are imported, representing an important part of the total cost of the treatment of complex patients in public hospitals [36].

Negotiations between public managers and medical companies are necessary to ensure the attainment of good-quality disposable endoscopic materials at lower costs. If the cost of disposable endoscopic materials decreased by $10 \%$, there would be a savings of US $\$ 1,196.66 \pm 285.39$, reducing the ICUR by $17 \%$ relative to the reference ICUR. Thus, this result represents an area of potential cost reduction for POEM.

Regarding the second reason, public hospitals are maintained by the System Unit Health (Sistema Único de SaúdeSUS). This system is financed by the government, making it a reference for private systems in the country. The goal of the SUS is to ensure comprehensive care for patients, prioritizing strategies for public health conditions. In this context, surgical instruments are considered as items of lower importance, and the purchase of new products is a long-term process. Thus, the vast majority of these instruments have depreciated, and their cost is incorporated throughout the process, justifying the lower cost of LHM in the intraoperative period.

A total of $14 \mathrm{AEs}(35 \%)$ were observed, which is higher than the rate reported in the literature. Of these, $64.3 \%$ were in the POEM group and $35.7 \%$ were in the LHM group. latrogenic perforations of the mucosa were responsible for $14 \%$ of complications in the POEM group, thus increasing the cost of this procedure, especially due to the greater number of clips used to close the lesion. Pneumothorax was the main major surgical complication in LHM, which impacted the increase in the cost of this group too. 
The institutional experience with LHM is more consolidated than with POEM, with a protocol with the treatment guidelines for the main adverse surgical events. The lack of expertise with management of POEM complications had a direct impact on postoperative costs (POEM US\$823.99 vs LHM US\$474.75, $P<$ $0.001)$, because extra resources were used, including imaging exams to assess contrast leakage.

Therefore, hospital costs are inversely proportional to technical and clinical experience: the lower the level of expertise, the higher the institutional cost. Our sensitivity analysis ( $\triangleright$ Fig. 2) reinforces this condition, because the clinical success rate for POEM decreased the ICUR by $17 \%$, given that the overall cost of treatment was $5.5 \%$ lower. This finding was also confirmed by an economic evaluation, which indicated that high performance levels for POEM will decrease complication rates, directly impacting the reduction in hospital costs [20].

Cost-effectiveness is difficult to define but is generally understood as good value or good results not costing much money. Brazil has not officially adopted a willingness-to-pay threshold; however, one study [37] has reported that there is an implied threshold of one to three times the Brazilian gross domestic product. Therefore, we can consider POEM a cost-effective technology in a time horizon of 1 year, as reported in the literature $[19,20]$.

\section{Conclusion}

POEM is more cost-effective than LHM over a 1-year time horizon. POEM costs can be minimized by reducing the cost of the endoscopic materials and improving experience with this procedure.

\section{Competing interests}

The authors declare that they have no conflict of interest.

\section{References}

[1] Lake JM, Wong RKH. Review article: the management of achalasia a comparison of different treatment modalities1. Aliment Pharmacol Ther 2006; 24: 909-918

[2] Vaezi MF, Pandolfino JE, Vela MF. ACG Clinical Guideline: Diagnosis and Management of Achalasia. Am J Gastroenterol 2013; 108: 12381249

[3] Gunasingam N, Perczuk A, Talbot M et al. Update on therapeutic interventions for the management of achalasia. J Gastroenterol Hepatol 2016; 31: 1422-1428

[4] Richter JE. Achalasia - An Update. J Neurogastroenterol Motil 2010; 16: $232-242$

[5] Winter H, Shukla R, Elshaer $M$ et al. Current management of achalasia - A review. Br J Med Pract 2015; 8: a810. https://www.bjmp.org/content/current-management-achalasia-review

[6] Pandolfino JE, Gawron AJ. Achalasia. JAMA 2015; 313: 1841

[7] Anefalos A, Herbella FAM, Patti MG. Upper esophageal sphincter motility and thoracic pressure are determinants of pressurized waves in achalasia subtypes according to the Chicago Classification. World J Surg 2020; 44: 1932-1938
[8] Jung H-K, Hong SJ, Lee OY et al. 2019 Seoul Consensus on Esophageal Achalasia Guidelines. J Neurogastroenterol Motil 2020; 26: 180-203

[9] Tsuboi K, Hoshino M, Srinivasan A et al. Insights gained from symptom evaluation of esophageal motility disorders: a review of 4,215 patients. Digestion 2012; 85: 236-242

[10] Sinan H, Tatum RP, Soares RV et al. Prevalence of respiratory symptoms in patients with achalasia. Dis Esophagus 2011; 24: 224-228

[11] Coronel MA, Bernardo WM, de Moura DTH et al. The efficacy of the different endoscopic treatments versus sham, pharmacologic or surgical methods for chronic gastroesophageal reflux disease: a systematic review and meta-analysis. Arq Gastroenterol 2019; 55: 296305

[12] Gupta M, Ghoshal UC, Jindal S et al. Respiratory dysfunction is common in patients with achalasia and improves after pneumatic dilation. Dig Dis Sci 2014; 59: 744-752

[13] Bianchi ET, Sallum RAA, Szachnowicz $S$ et al. Heller-Pinotti, a modified partial fundoplication associated with myotomy to treat achalasia: technical and final results from 445 patients. Mini-invasive Surg 2017; 1: 153-159. doi:10.20517/2574-1225.2017.41

[14] Inaba CS, Wright AS. Laparoscopic Heller myotomy and Toupet fundoplication for achalasia. J Laparoendosc Adv Surg Tech 2020; 30: doi:10.1089/lap.2020.0158

[15] Inoue $\mathrm{H}$, Minami H, Kobayashi $\mathrm{Y}$ et al. Peroral endoscopic myotomy (POEM) for esophageal achalasia. Endoscopy 2010; 42: 265-271

[16] Montalvo-Javé EE, Crisanto-Campos BA, Tapia-Jurado J et al. Perspectiva actual de la cirugía endoscópica transluminal por orificios naturales (CETON) [A current perspective of natural orifices transluminal endoscopic surgery (NOTES)]. Rev Gastroenterol Peru 2016; 36: 242248

[17] Nesargikar PN, Jaunoo SS. Natural orifice translumenal endoscopic surgery (N.O.T.E.S). Int J Surg 2009; 7: 232-236

[18] Pasricha P, Hawari R, Ahmed I et al. Submucosal endoscopic esophageal myotomy: a novel experimental approach for the treatment of achalasia. Endoscopy 2007; 39: 761-764

[19] Miller HJ, Neupane R, Fayezizadeh M et al. POEM is a cost-effective procedure: cost-utility analysis of endoscopic and surgical treatment options in the management of achalasia. Surg Endosc 2017; 31: 1636-1642

[20] Greenleaf EK, Winder JS, Hollenbeak CS et al. Cost-effectiveness of per oral endoscopic myotomy relative to laparoscopic Heller myotomy for the treatment of achalasia. Surg Endosc 2018; 32: 39-45

[21] Delgado AAA, de Moura DTH, Ribeiro IB et al. Propofol vs traditional sedatives for sedation in endoscopy: A systematic review and metaanalysis. World J Gastrointest Endosc 2019; 11: 573-588

[22] Hathorn KE, Chan WW, Aihara $\mathrm{H}$ et al. Determining the safety and effectiveness of electrocautery enhanced scissors for peroral endoscopic myotomy (with video). Clin Endosc 2020; 53: 443-451. doi:10.5946/ce.2019.214

[23] Martins RK, Ribeiro IB, de Moura DTH et al. Peroral (POME) or surgical myotomy for the treatment of achalasia: a systematic review and meta-analyis. Arq Gastroenterol 2020; 57: 79-86

[24] Weusten BLAM, Barret M, Bredenoord AJ et al. Endoscopic management of gastrointestinal motility disorders - part 1: European Society of Gastrointestinal Endoscopy (ESGE) Guideline. Endoscopy 2020; 52: 498-515

[25] Runge TM, Ichkhanian Y, Khashab MA. POEM for achalasia: endoscopic myotomy enters its golden age, and we are taking NOTES. Gastrointest Endosc 2020; 91: 1045-1049.e1

[26] Werner YB, Hakanson B, Martinek J et al. Endoscopic or Surgical myotomy in patients with idiopathic achalasia. N Engl J Med 2019; 381: $2219-2229$ 
[27] Noguchi K, Gel Y, Brunner E et al. nparLD: An R Software Package for the Nonparametric Analysis of Longitudinal Data in Factorial Experiments. J Stat Software 2012; 50: 1-23

[28] Noguchi K, Latif M, Thangalevu K et al. Nonparametric Analysis of Longitudinal Data in Factorial Experiments. New York: John Wiley \& Sons;

[29] Swanström LL. Achalasia: treatment, current status and future advances. Korean J Intern Med 2019; 34: 1173-1180

[30] Martins RK, Bernardo WM, Moura ET et al. Peroral endoscopic myotomy versus surgical myotomy for the treatment of achalasia: Systematic review and meta-analysis. Gastrointest Endosc 2018; 87: AB538-AB539

[31] Mohan BP, Ofosu A, Chandan S et al. Anterior versus posterior approach in peroral endoscopic myotomy (POEM): a systematic review and meta-analysis. Endoscopy 2020; 52: 251-258

[32] Hashimoto R, Inoue $\mathrm{H}$, Shimamura $\mathrm{Y}$ et al. POEM as salvage therapy in patients with achalasia refractory to endoscopic or surgical therapy is technically feasible and safe: A systematic review and meta-analysis.
Dig Endosc 2020: doi:10.1111/den.13643 [Epub ahead of print. PMID: 32012360]

[33] Farias GFA, de Moura DTH, de Moura ETH et al. Peroral endoscopic myotomy (POEM): a comparative study between Chagasic and idiopathic achalasia. Endosc Int Open 2020; 08: E506-E512

[34] Antonini Ribeiro R, Lavanholi Neyeloff J, Itria A et al. Diretriz metodológica para estudos de avaliação econômica de tecnologias em saúde no Brasil. J Bras Econ da Saúde 2016; 8: 174-184

[35] Ministério da Saúde. Diretrizes metodológicas: diretriz de avaliação econômica. 2 ed. Brasília: 2014: https://bvsms.saude.gov.br/bvs/ publicacoes/diretrizes_metodologicas_diretriz_avaliacao_economica.pdf

[36] Kahaleh M, Xu M-M, Zamarripa F et al. POEM in Latin America. J Clin Gastroenterol 2019; 53: e352-e355

[37] Schwarzer R, Rochau U, Saverno KJ et al. Systematic overview of costeffectiveness thresholds in ten countries across four continents. J Comp Eff Res 2015; 4: 485-504 